\title{
The Italian Version of Smartphone Addiction Inventory (SPAI-I) for Adolescents: Confirmatory Factor Analysis and Relation with Self-Control and Internalized-Externalized Symptoms
}

\author{
Giulia Bassi $^{1,2}$ (D) Adriana Lis ${ }^{1}$ (D) Tatiana Marci $^{1}$ (D) Silvia Salcuni ${ }^{1}$ (D)
}

Accepted: 8 November 2021

(C) The Author(s) 2021

\begin{abstract}
The increased smartphone use in adolescence has led clinicians and researchers to carry out in-depth studies on the matter. Adolescents seem to be at risk of smartphone addiction because they are yet to develop self-control in smartphone use. This psychometric study aimed at examining the levels of validity evidence for the Smartphone Addiction Inventory-Italian (SPAI-I) version for adults, among adolescents. Confirmatory Factor Analysis confirmed the factor structure of the SPAI-I version for adults among adolescents but not the exploratory factor structure for adults of the original Smartphone Addiction Inventory (SPAI). Convergent validity was assessed by examining the relationship between SPAI-I, self-control, and internalized and externalized problems. A total of 446 Italian adolescents (mean age $=16.04, \mathrm{SD}=1.72,36.3 \%$ males) completed the Self-Restraint Subscale of the Adolescent Self-Consciousness and the Strengths and Difficulties Questionnaires-with a specific focus on the subscales of internalized and externalized problems. Present findings suggested that the SPAI-I version could be used to assess smartphone overuse among adolescents according to a multidimensional perspective.
\end{abstract}

Keywords Smartphone Addiction Inventory-Italian version · Confirmatory Factor Analysis · Internalized symptoms $\cdot$ Externalized symptoms $\cdot$ Self-control $\cdot$ Adolescents

\section{The Phenomenon of Smartphone Addiction in Adolescence}

Nowadays, adolescents express their thoughts through smartphones, using many types of applications (e.g., WhatsApp, Facebook, YouTube), especially those for cultivating relationships, thereby reporting that they would not be able to live without them (Bittman et al., 2009). Indeed, smartphone use is increasing exponentially worldwide, including

Giulia Bassi

giulia.bassi@phd.unipd.it

1 Department of Developmental and Socialization Psychology, University of Padova, Via Venezia 12, 35131 Padova, Italy

2 Fondazione Bruno Kessler, Via Sommarive 18, 38123 Trento, Italy 
in Italy, and particularly among adolescents. According to Istat, 85.8\% of Italian adolescents aged 11-17 years have constant access to a smartphone, and over $72 \%$ can access the Internet via smartphone. In addition, $75 \%$ of Italian adolescents use a smartphone during school hours, and $98 \%$ use it after midnight. Indeed, $45 \%$ of adolescents sleep with their smartphone under their pillow, and $60 \%$ check their smartphone during the night. Statistics reveal that $57 \%$ of adolescents use their smartphone within 10 min of waking up, and $80 \%$ fall asleep holding their smartphone in their hand (Rapporto Censis sulla situazione sociale del Paese, 2018). Evidence has shown that addiction to the smartphones in adolescents can be associated with adverse and problematic effects (Al-Barashdi et al., 2015). Therefore, the increased use of smartphones in adolescence has led clinicians and researchers to study this phenomenon in-depth. However, the terminology regarding problematic smartphone use is inconsistent, and a general consensus is lacking. For example, the literature revealed a widespread usage of terms, such as addiction, excessive, overuse, compulsive, compensatory, and problematic (Kardefelt-Winther, 2014; Widyanto \& Griffiths, 2006). Nevertheless, smartphone addiction is conceptualized as different from substance abuse, and it is related to behavior and not substance dependence (van Deursen et al., 2015). In behavioral addictions, the behavior seems to act as a reward in which the presence of thinking of using smartphones is predominant (van Deursen et al., 2015). Furthermore, literature did not reach a consensual definition of smartphone addiction symptoms because, even though a wide range of problematic behaviors emerged, they cannot be considered as indicators (Takao et al., 2009). Thus, further exploration regarding smartphone addiction symptoms is required. Most authors perceived this behavioral addiction as a human-machine interaction, which involves individuals in smartphone overuse to the extent that they neglect other areas of life (Billieux et al., 2008; Griffiths, 2005; Lin et al., 2014). For example, according to some authors, smartphone addiction is defined as an excessive usage of smartphones that interferes with the adolescents' daily functioning (Demirci et al., 2014). The revision of the growing body of studies regarding symptoms related to smartphone overuse seems to suggest that this phenomenon should be conceptualized and measured as a multidimensional construct (Al-Barashdi et al., 2015).

\section{Instruments Designed to Measure Smartphone Addiction}

Most studies have been carried out through the use of instruments designed to measure difficulties, which emerged from Internet use, but not specifically from smartphone use. Therefore, a multidimensional instrument to help in determining the extent of smartphone addiction in Italian adolescents is needed. As regards the Italian population, in particular, three tools were developed for assessing smartphone addiction: firstly, the Smartphone Addiction Scale-Short Version (SAS-SV; De Pasquale et al., 2017), a 10-item monodimensional, self-report questionnaire, in which the metric validity was evaluated in a wide sample of Italian adolescents and college students (mean age $=18$ years old); secondly, the Smartphone Application-Based Addiction Scale (SABAS; Csibi et al., 2018), also consisting of a monofactorial structure, although with a specific focus on compulsivity; and lastly, the Smartphone Addiction InventoryItalian (SPAI-I; Pavia et al., 2016) version, which was the only multidimensional selfadministered instrument validated in Italy. SPAI-I was validated on a sample of 498 Italian college students, and the version includes 24 items out of the 26 items from the original scale (Pavia et al., 2016). An exploratory confirmatory cross-validation 
strategy suggested a five-factor solution: time-spent, compulsivity, daily life interference, craving, and sleep interference. The initial validation of SPAI was conducted on 283 Taiwanese University students (Lin et al., 2014), and only an exploratory factor analysis (EFA) was carried out, yielding four-factor: compulsive behavior, functional impairment, withdrawal, and tolerance, encompassing multiple aspects of smartphone addiction (Lin et al., 2014). SPAI had also shown adequate psychometric properties, and it appeared to be a reliable screening tool for the investigation of smartphone addiction. Validation of the SPAI original version (Simò-Sanz et al., 2018) was also performed on a Spanish adult sample of 2,958 people $(65.3 \%$ female, $82 \%$ bachelor's or postgraduate degree, and mean age of $27.96 \pm 12.1$ years). Results confirmed the four-factor model (compulsive behavior, functional impairment, withdrawal, and tolerance) raised by Lin et al. (2014) in their study. Therefore, although SPAI and SPAI-I were both carried out on college students, their factor structure did not agree.

\section{Self-Control, Internalized and Externalized Symptoms in the Use of Smartphone in Adolescence}

Literature reveals how internalized and externalized symptoms can pertain to smartphone addiction during adolescence. More specifically, internalized symptoms related to smartphone use appear to express themselves as symptoms of depression and anxiety (Boumosleh \& Jaalouk, 2017; Mitchell \& Hussain, 2018) and also can cause sleep disturbances (Thomee et al., 2011). Meanwhile, externalized symptoms can lead to problems with social and academic behaviors (Hawi \& Samaha, 2016; Seo et al., 2016). Self-control can also pertain to smartphone addiction in adolescence. Self-control is defined as one's ability to change thoughts, emotions, and impulses to follow social norms and personal values and to support the pursuit of long-term goals, despite short-term rewarding temptations, distractions, or aversive states (Baumeister \& Vohs, 2003; Baumeister et al., 2007). Successful self-control brings benefit for personal and social thriving, whereas self-control failure might lead to adjustment problems, unsatisfactory academic performance, low well-being, and so forth (de Ridder et al., 2017; Duckworth, \& Seligman, 2005; Hofmann et al., 2014; Tangney et al., 2004). Adolescents, during this specific developmental period, show poor self-control and regulation strategies predisposing them toward increased risk-taking behaviors and adjustment difficulties (Ahmed et al., 2015). Moreover, they can also experience a decrease in self-restraint ability and impulsive behaviors, which might become critical barriers to healthy relationships and mental well-being (Won et al., 2013). As adolescents could be seen as especially prone to low self-control, due to the physiological immaturity of the brain's prefrontal cortex (Gazzley \& Rosen, 2016), problematic smartphone use may represent a risk for the development of self-control capacity. Indeed, one of the most significant issues regarding smartphone addiction is its uncontrollability of usage. Since impulsivity is an important potential contributory factor to self-control, several studies have highlighted that the impulsiveness of smartphone addiction would be related to self-control (Hamilton et al., 2014). Therefore, adolescents seem to be more at risk of smartphone addiction as compared to adults because they have yet to acquire self-control during development and in smartphone use (Cha \& Seo, 2018). 


\section{Objectives}

The purpose of the current study was to evaluate the psychometric properties of the SPAI-I version - a multidimensional tool—for adults in a sample of Italian adolescents. More specifically, the aims of the current study were two-fold:

- To test the factorial structure of the SPAI-I for adults in a sample of Italian adolescents;

- To assess its convergent validity in a sample of Italian adolescents.

Therefore, a series of Confirmatory Factor Analyses (CFAs) have been performed, and the association between SPAI-I and its dimensions with a series of external criteria measures related to self-control and internalizing and externalizing problems has been examined, by using a structural equation modeling (SEM) approach.

\section{Material and Methods}

\section{Inclusion and Exclusion Criteria}

The inclusion criteria for participating in the current study were articulated as follows:

- Participation was limited to the high school students only.

- The possession of their own smartphone.

There were no refusals to participate, and therefore, there were no exclusion criteria, except for those students who were absent during the administration of the instruments.

\section{Participants}

According to the World Health Organization's definition of adolescence, this developmental phase corresponds roughly to the period between the ages of 10 and 19 years (World Health Organization, 1986). Indeed, the study involved 486 adolescents recruited from high schools in the North of Italy. However, 40 participants did not complete the measures correctly and entirely. Therefore, the final sample included 446 Italian respondents aged between 13 and 19 years $\left(\mathrm{M}_{\text {age }}=16.04, \mathrm{SD}=1.72\right)$. In this sample, all participants are Italian and presented a middle socio-economic level. Moreover, $79.4 \%$ of adolescents attend classical, scientific, art, health, and social care high schools. In addition, $20.6 \%$ of them attend professional high schools, such as computer sciences and commercial studies.

\section{Procedure}

The study procedure was conducted in compliance with the Declaration of Helsinki (Italian law 196/2003, UE GDPR 679/2016). The Interdepartmental Ethical Committee of Psychology of Padova University approved the project (number 2322, 6 June 2017), arguing that there were no critical ethical issues. The school principal, as well 
as the participants' parents, signed a written informed consent agreeing to the participation of the institution and the adolescents, respectively. Participants provided their oral assent before participation, since students completed the online questionnaire in a classroom designated for computer use, under the supervision of the teacher and the researcher. The online survey - with validated questionnaires within-was developed by the author's departmental IT staff. All participants were informed that the data were confidential and that they could omit any information they did not wish to give and could withdraw from the study at any moment.

\section{Measures}

The Self-Restraint Subscale of Adolescent Self-Consciousness Questionnaire (ASC; Nie $\&$ Ding, 2009; Nie et al., 2014) represents one of the nine subscales of the ASC, containing 11 items, designed to assess different aspects of the self of adolescents aged between 11 and 19 years. Each item is rated on a 5-point Likert scale, ranging from 1 ("not like me at all") to 5 ("like me very much"). This subscale was used to assess adolescents' ability to control their thoughts/attention, emotions, and impulses. Higher scores indicate a higher level of self-consciousness and self-control. The ASC questionnaire has been validated on adolescent samples in Chinese and Italian contexts, showing good psychometric properties (Delvecchio et al., 2014, 2015). Using a CFA, a recent cross-cultural study has revealed that the self-restraint subscale is monodimensional (Delvecchio et al., 2014). In this study, participants answered the existing Italian version of the scale (Nie et al., 2014), and the polychoric Cronbach's $\alpha$ was $0.76(95 \%$ $\mathrm{CI}=[0.73,0.80])$.

The Strengths and Difficulties Questionnaire (SDQ; Goodman et al., 2010) is a brief questionnaire consisting of 25 items, for assessing strengths and difficulties in the psychological adjustment among children and adolescents aged between 8 and 17 years (www.sdqinfo.com). Items are rated on a 3-point-Likert scale from 0 ("not true") to 2 ("certainly true") and are summed to provide 5 component scores. These latter scales, namely emotional symptoms, conduct problems, hyperactivity-inattention, peer problems, and prosocial behaviors, are each composed of 5 items. An overall total difficulties score is obtained by adding together the scores for four components of behavioral problems (Goodman, 1999). For this study, internalizing (i.e., emotional symptoms and peer problems) and externalizing problems (i.e., conduct problems and hyperactivity-inattention) (Goodman et al., 2010), as well as the total difficult score, were considered. Higher scores on internalizing and externalizing symptoms indicate more problematic attributes. In the current study, polychoric Cronbach's $\alpha$ was $0.80(95 \% \mathrm{CI}=[0.77,0.83])$ and $0.85(95 \% \mathrm{CI}=[0.83,0.87])$ for externalizing and internalized problems, respectively.

The Smartphone Addiction Inventory-Italian (SPAI-I; Pavia et al., 2016) version is a 24-item self-report questionnaire designed to assess smartphone addiction in adolescence. It consists of 5 scale, namely time-spent (items: 1, 2, 3, 4), compulsivity (items: $5,10,20,23$ ), daily life interference (items: 6, 7, 9, 12, 13, 15, 17, 18), craving (items: $11,14,16,19,21$ ), and sleep interference (items: 8, 22, 24). Each item is scored using a 4-point Likert scale ranging from 1 ("strongly disagree") to 4 ("strongly agree"). Scores across items are averaged to provide a 5 composite score and a total score. More details are reported in the "Introduction" section. The Cronbach's alpha reliability coefficient 
of the original SPAI ranged from 0.70 to 0.78 before computing the factor analysis, whereas the reliability of SPAI-I among adults ranged from 0.70 to 0.81 .

\section{Data Analysis}

Analyses were performed using R (R Core Team, 2019).

To evaluate the factor structure of SPAI-I, it has been tested: (a) a single-factor model (baseline model), in which items were loaded on a single latent factor; (b) a fourfactor solution, in which items tap the four dimensions indicated by Lin et al. (2014); and (c) a five-factor solution, with items loading on factors as indicated by Pavia et al. (2016) in the Italian version. All models were carried out using the weighted least squares mean and variance (WLSMV) estimator suitable for ordinal data (Flora \& Curran, 2004). To evaluate models fit, a series of goodness-of-fit indices was computed, including the degrees of freedom ratio $\left(\chi^{2} / \mathrm{df}\right)$, the comparative fit index (CFI), the Tucker Lewis index (TLI), the root mean square error of approximation (RMSEA), and the standardized root mean square residual (SRMR). Following the Schermelleh-Engel et al. (2003) guidelines, a $\chi^{2} / \mathrm{df}<3$, values of RMSEA and SRMR less than or equal to 0.06 , and a CFI and TLI greater than 0.95 indicate a good fit of the model. All models were estimated using the lavaan package (Rosseel, 2012). Based on the model selected, the internal consistency has been evaluated through Cronbach's alpha and the greatest lower bound (GLB) computed on the polychoric correlation matrix (Ten Berge \& Sočan, 2004).

To test external validity, first Pearson's bivariate correlations were carried out between the SPAI-I dimensions, the SPAI-I total score, self-control (assessed by the ASC questionnaire), and internalizing and externalizing symptoms (assessed by the SDQ questionnaire). The significance of association between variables has been taken into account, also considering the power of their linkage following Cohen's guidelines (1988), in which a value of 0.1 reflects a "small" effect size, 0.3 a "medium" effect size, and 0.5 a "large" effect size. Then, the association between SPAI-I with the external criterion measures was evaluated by using a SEM approach for observed variables (i.e., path analysis). In particular, two models were estimated: (1) a first model (M1) with the SPAI-I total score as a predictor (exogenous variables), externalized and internalized symptoms, and self-control as dependent variables (endogenous variables) and (2) a second model (M2) including the five related SPAI factors as predictors of the external measures criteria (i.e., internalized and externalized symptoms and self-control). This procedure allowed us to assess the association with several outcomes that may potentially influence each other simultaneously (M2, M1) beyond to take the correlation among SPAI-related dimensions into account and thus evaluate the unique contribution of each factor in predicting the external measures. Both models were fitted using the robust maximum likelihood (MLR) estimator (Satorra \& Bentler, 1994). A brief representation of path analyses models is presented in the Supplementary Materials (Figure S1). 
Table 1 Descriptive statistics and confidence of interval (CI) of the SPAI-I version factors

\begin{tabular}{lrrr}
\hline SPAI-I & \multicolumn{2}{l}{ Total } & \\
\cline { 2 - 4 } Five factors & $\mathrm{M}$ & $\mathrm{SD}$ & $95 \% \mathrm{CI}$ \\
\hline Time-spent & 7.97 & 2.59 & $7.73,8.21$ \\
Compulsivity & 5.60 & 1.90 & $5.42,5.78$ \\
Daily life interference & 12.14 & 3.77 & $11.8,12.5$ \\
Craving & 8.36 & 3.03 & $8.08,8.64$ \\
Sleep interference & 4.22 & 1.88 & $4.05,4.39$ \\
Total score & 38.29 & 10.75 & $37.3,39.3$ \\
\hline
\end{tabular}

$N=446 ; M$ mean, $S D$ standard deviation, $C I$ confidence interval

Table 2 Fit indices for the confirmatory factor models tested for the SPAI

\begin{tabular}{lcccccc}
\hline & $\chi 2 / d f$ & $p$ & $C F I$ & $T L I$ & SRMR & RMSEA [90\% CI] \\
\hline M0: One factor & 3.04 & $<.001$ & .918 & .910 & .076 & $.068[.062, .073]$ \\
M1: Four factors & 2.53 & $<.001$ & .940 & .933 & .068 & $.059[.053, .064]$ \\
M2: Five factors & 2.05 & $<.001$ & .960 & .954 & .059 & $.048[.042, .055]$ \\
\hline
\end{tabular}

$N=446 . \chi 2 / d f$ chi-square/degree of freedom, $C F I$ comparative fit index, TLI Tucker-Lewis index, SRMR standardized root mean square residual, RMSEA root mean square of approximation

\section{Results}

\section{Descriptive Statistics}

Most of the items showed a right-skewed distribution, supporting the use of a WLSMV estimator (Rhemtulla et al., 2012). The main descriptive statistics for each item (i.e., mean, standard deviation, skewness) are provided within the Supplementary Material section (Table S1). Table 1 shows mean, standard deviation, and CI at 95\% level for the SPAI-I total score and its five dimensions among the total sample.

\section{Confirmatory Factor Analysis}

Overall, the CFA ${ }^{1}$ performed on the one-factor model yielded unacceptable fit, according to the established cut-off values (Table 2). After testing for the four-factor solution (M1, Table 2), the model slightly improved in all the considered fit indices. However, the covariance matrix of latent variables was not positive define. The subsequent five-factor model (M2, Table 2) yielded a good fit in all the considered indexes; therefore, it was considered more adequate in the current sample. All factor loadings were large and significant at the $1 \%$ level. Furthermore, internal consistency was good with ordinal Cronbach's alphas ranging from 0.79 to 0.85 and ordinal GLB ranging from 0.83 to 0.88 (Table 3).

\footnotetext{
1 Another analysis on participants under the age of $19(n=407)$ was run in order to avoid overlapping with the Pavia et al. (2016) sample. The results equal to those obtained from the whole sample $(\chi 2 / \mathrm{df}=1.94$, $\mathrm{CFI}=962, \mathrm{TLI}=.957, \mathrm{RMSEA}=.0 .48[.042-.055]$.
} 
Table 3 Reliability indices for the five factor of the SPAI-I version

\begin{tabular}{lll}
\hline Factors & Cronbach's alphas [95\% CI] & $\begin{array}{l}\text { Greatest } \\
\text { lower } \\
\text { bound }\end{array}$ \\
\hline Time-spent & $.79[0.75,0.82]$ & .83 \\
Compulsivity & $.81[0.78,0.84]$ & .84 \\
Interference in daily life & $.82[0.79,0.84]$ & .86 \\
Craving & $.85[0.82,0.87]$ & .88 \\
Sleep interference & $.85[0.82,0.87]$ & .85 \\
\hline
\end{tabular}

Both indexes are calculated on the polychoric correlation matrix

Table 4 Two-tailed correlations between self-restraint subscale of adolescent self-consciousness questionnaire (ASC), the strengths and difficulties questionnaire (SDQ) scores, the SPAI-I version total score, and its dimensions

\begin{tabular}{|c|c|c|c|c|c|c|c|c|c|}
\hline & 1 & 2 & 3 & 4 & 5 & 6 & 7 & 8 & 9 \\
\hline 1. SPAI-I total score & 1 & & & & & & & & \\
\hline 2. Time-spent & .83 & 1 & & & & & & & \\
\hline 3. Compulsivity & .81 & .65 & 1 & & & & & & \\
\hline 4. Interference in daily life & .86 & .57 & .59 & 1 & & & & & \\
\hline 5. Craving & .86 & .70 & .64 & 64 & 1 & & & & \\
\hline 6. Sleep interference & .65 & .42 & .51 & .49 & .38 & 1 & & & \\
\hline 7. Externalizing problems & .45 & .44 & .30 & .41 & .32 & .34 & 1 & & \\
\hline 8. Internalizing problems & .31 & .25 & .18 & .30 & .22 & .30 & .43 & 1 & \\
\hline 9. Self-control & -.52 & -.50 & -.34 & -.43 & -.40 & -.40 & -.73 & -.34 & 1 \\
\hline
\end{tabular}

$N=446 ;$ all $p$ values are significant at the .05 level

\section{Convergent Validity}

In terms of convergent validity, as reported in Table 4, correlations between SPAI-I, selfcontrol, and internalizing and externalizing behaviors are all significant at the 0.05 level and characterized by small to large effect size.

Next, two path analyses were performed. One with the SPAI-I total score as an independent variable and a second model including all five SPAI-I dimensions. The SPAI-I total score was significantly and positively related to both externalizing $(B=0.453$, $p<0.001)$ and internalizing behaviors $(B=0.310, p<0.001)$ and negatively related to selfcontrol $(B=-0.515, p<0.001)$. The subsequent model testing the linkage between each of the five SPAI-I with external criterion measures shows a significant positive association between interference in daily life and sleep interference with internalizing symptoms $(B=0.186, p=0.007 ; B=0.215, p<0.001)$ whereas time-spent, interference in daily life, and sleep interference with externalizing symptoms $(B=0.346, p<0.001, B=0.244$, $p<0.001 ; B=0.156, p=0.003)$. Furthermore, a negative and meaningful association was found between time-spent $(B=-0.390, p<0.001)$, interference in daily life $(B=-0.179$, $p=0.004)$, and sleep interference $(B=-0.206, p<0.001)$ but a positive association between compulsivity and self-control $(B=0.134, p=0.019)$. 


\section{Discussion}

The aim of the present study was to examine the psychometric properties of the Smartphone Addiction Inventory-Italian (SPAI-I), originally developed for adults, in a sample of Italian adolescents. Using a CFA, the SPAI-I version factor structure obtained in previous studies on Italian college students was confirmed for the Italian adolescents' sample, maintaining the five-factor structure. Therefore, results confirmed that the five-factor structure fits better than the four-factor structure of the SPAI original version. Furthermore, the five-factor structure of SPAI-I showed good internal consistency. A possible reason may be the fact that the original SPAI structure was examined using only 24 items rather than 26 items. Another possible reason why the model fits better in the SPAI-I version structured than in the original SPAI version may be the difference in the cultural background (i.e., Italian and Taiwanese population). Cultural differences may be ascribed to issues regarding translation and variation in the interpretation of items among individuals of different cultures. Indeed, European and Asian countries present differences regarding their cultures, values, geographical location, and developmental paths. Another potential explanation may be that the literature has not yet acquired a consensual definition of the term and symptoms regarding smartphone addiction. Consequently, different symptoms and signs could be identified differently, across several populations or contexts. For instance, in the original SPAI version, the factor functional impairment contains items regarding sleep and time management issues. Diversely, in the SPAI-I version, all items regarding sleep problems are concentrated entirely on a specific factor (i.e., sleep interference), whereas items regarding time management issues converge in the factor daily life interference. Relationships with self-control and internalizing and externalizing symptoms go in the expected directions both for the SPAI-I total score and its dimensions, contributing to assess the external validity of the above-mentioned tool. Moreover, the several findings that emerged from this association also allowed the development of some interpretations since excessive smartphone use could lead adolescents to show a behavioral addiction, thereby presenting several symptoms. Previous studies reported that in smartphone addiction, both internalized and externalized symptoms were noted: externalized symptoms in the form of aggressiveness and impulsiveness on the one hand, and internalized symptoms in the form of anxiety and depression on the other (Boumosleh \& Jaalouk, 2017; Mitchell \& Hussain, 2018). Interestingly, when testing the path model, the dimensions of interference in daily life and the sleep interference showed a significant and positive association with internalizing and externalizing symptoms, indicating the importance of understanding the potential underlying psychological mechanisms. In particular, the interference in daily life dimension refers to the adolescents' inability to take their minds off their smartphones and to perform other activities during their everyday life (Pavia et al., 2016). The sleep interference dimension refers to being connected to their smartphone even during the night, which could lead to the development of some sleep disturbances (Pavia et al., 2016). Moreover, the time-spent dimension presented a significant and positive relation only with externalizing problems. Specifically, time-spent relates to the difficulty of interrupting smartphone use while also creating a sense of time distortion, as a result of dedicating excessive time and resources to smartphone use (Pavia et al., 2016). Thus, these three dimensions related to internalizing and externalizing problems would appear to bear similarities to certain criteria for "substance-related and addictive disorders," as seen in the Diagnostic and Statistical Manual of Mental Disorder-5 (DSM-5; American Psychiatric Association, 2013), in which behaviors seem to be focused on the use of the smartphone. As for self-control, 
one of the most significant issues regarding smartphone addiction is its uncontrollability of usage. Since impulsivity is an important potential contributory factor to self-control, several studies have highlighted that self-control is involved in the impulsiveness of smartphone addiction (Hamilton et al., 2014; Roberts \& Pirog, 2012). In the present study, the SPAI-I total score and its dimensions were significantly negatively related: higher self-control and lower smartphone addiction. The most interesting results concerned the negative linkage between time-spent, interference in daily life, sleep interference, and self-control. The more adolescents spent time on their smartphones, the more there is interference in daily life and sleep, and the levels of self-control decrease. For example, previous studies investigated the association between self-control and smartphone usage: behaviors such as sending messages during school hours (Wei et al., 2012), checking their notifications on their smartphone screen (Berger et al., 2018), and manifesting externalized problems (Sinha, 2009) were found to be associated with poor self-control. In this regard, in the path analysis, $C$ compulsivity showed a significant and positive association with self-control. Hypothetically, this relation could be the result of the particular developmental period that adolescents are facing, in which self-control capacities are still being constructed and are, in some ways, "controlled," not entirely regulated and not spontaneous. Thus, as in compulsivity, there is an emphasis on controlling one's own actions, such as in the obsessive compulsive functioning. To this extent, these findings need to be considered in a prevention program for supporting adolescents in their coping strategies, with a specific focus on self-control capacities and regulation skills. Notwithstanding, further exploration is needed, by including self-control as a valuable variable in smartphone excessive use. Overall, the findings of the present study suggest that the SPAI-I version represents a valid and reliable tool for assessing adolescents' smartphone overuse from a multidimensional perspective and, particularly, for the analyses of population comparisons. In this context, it is worth noting that tools, such as the SPAI-I version, could be addressed on adolescent samples since recent studies have focused only on the adult population (Lin et al., Pavia et al., 2016; Simò-Sanz et al., 2018). Indeed, the literature suggests that adolescents seem to be more at risk of developing a behavioral addiction as in smartphone use since they are going through an important psychophysical developmental period.

\section{Limitations and Strengths}

Several limitations should be considered in this study. First, this is a cross-sectional study. Nevertheless, it has been useful for the identification of relevant variables in the context of smartphone use in adolescents, such as self-control and the presence of internalized and externalized problems, which could be used for future longitudinal studies. Second, the study was carried out on a community sample, and thus, the results cannot be generalized. Indeed, only data from high school participants, who were volunteers, were collected in this study, which restricts the generalizability of findings related to the SPAI-I version psychometric properties. Future studies could focus on patients at risk of smartphone addiction or on those who present some pattern of social withdrawing symptoms (i.e., Hikikomori). In addition, the sample consisted mainly of females, which could limit the external validity of the instrument, as emerged from Pavia et al.'s study (2016). Moreover, given the complexity number of parameters being estimated simultaneously and in light of the complexity of the SPAI model (i.e., 24 items shared across 5 factors), the sample size was inadequate to perform multigroup (MG) analyses. More specifically, the boy's group (including 
164 participants) does not meet the sample size requirements (see Boomsma \& Hoogland, 2001; Marsh \& Hocevar, 1988; Nunnally, 1967) recommended to perform the first step of MG-CFA (i.e., testing the factor structure of the questionnaire separately in each group). Therefore, future studies should perform an MGCFI analysis in order to evaluate gender invariance regarding smartphone addiction among a more balanced sample. Indeed, future works should focus on examining gender differences in smartphone addiction since the literature has scarcely addressed them (Fischer-Grote et al., 2019). Last, other forms of substance addictions (e.g., excessive alcohol and drug use) have been not investigated among this sample as well as other behavioral addictions (e.g., videogames). Therefore, future works should take into consideration these addictions, especially the behavioral ones since they could lead to similar brain and behavioral changes as in smartphone addiction.

\section{Conclusion}

The five-factor structure of the SPAI-I version seems to include some of the DSM-5 "substance-related and addictive disorders" diagnosis criteria (American Psychiatric Association, 2013). In this context, the SPAI-I version may represent an important tool in the development of the addiction concept related to smartphone use, thereby creating a parallel between the addiction to smartphones and the addiction to the substances (Billieux et al., 2008). Therefore, this study could help to increase the awareness of symptoms and signs of smartphone addiction within a framework of potential behavioral addictive disorders. Also, this work provides a particular focus on several factors of smartphone use in adolescents, highlighting a model (i.e., SPAI-I version), which presents a multidimensional construct, rather than focusing on a monofactorial structure, as in SAS-SV (De Pasquale et al., 2017) and SABAS (Csibi et al., 2018) (i.e., compulsivity). Moreover, the SPAI-I version specifically addresses the adolescents' sample, since literature shows how smartphone use can alter the adolescents' behavioral patterns and psychophysical development. The SPAI-I version represents the only tool validated in Italy among adolescents, and thus, the SPAI-I version can be used to assess the degree of smartphone addiction as a behavioral addiction in the Italian adolescents' population.

Supplementary Information The online version contains supplementary material available at https://doi. org/10.1007/s11469-021-00705-w.

\section{Declarations}

Informed Consent All procedures followed were in accordance with the ethical standards of the responsible committee on human experimentation (institutional and national) and with the Helsinki Declaration of 1975, as revised in 2000 (5). Informed consent was obtained from all participants for being included in the study.

Conflict of Interest The authors declare no competing interests.

OSF Repository Dataset SPAI-I (Link for accessing the dataset: https://osf.io/5f3h2/?view_only=4fe95b993d 1243b3987c50a5dbd14c80)

Open Access This article is licensed under a Creative Commons Attribution 4.0 International License, which permits use, sharing, adaptation, distribution and reproduction in any medium or format, as long as you give appropriate credit to the original author(s) and the source, provide a link to the Creative Commons 
licence, and indicate if changes were made. The images or other third party material in this article are included in the article's Creative Commons licence, unless indicated otherwise in a credit line to the material. If material is not included in the article's Creative Commons licence and your intended use is not permitted by statutory regulation or exceeds the permitted use, you will need to obtain permission directly from the copyright holder. To view a copy of this licence, visit http://creativecommons.org/licenses/by/4.0/.

\section{References}

Al-Barashdi, H. S., Bouazza, A., \& Jabur, N. H. (2015). Smartphone addiction among university undergraduates: A literature review. Journal of Scientific Research and Reports, 4(3), 210-225. https://doi. org/10.9734/JSRR/2015/12245

American Psychiatric Association. (2013). Diagnostic and statistical manual of mental disorders (5th ed.). Author.

Ahmed, S. P., Bittencourt-Hewitt, A., \& Sebastian, C. L. (2015). Neurocognitive bases of emotion regulation development in adolescence. Developmental Cognitive Neuroscience, 15, 11-25. https://doi.org/ 10.1016/j.den.2015.07.006

Baumeister, R. F., Vohs, K. D., \& Tice, D. M. (2007). The strength model of self-control. Current Directions in Psychological Science, 16(6), 351-355. https://doi.org/10.1111/j.1467-8721.2007.00534.x

Baumeister, R. F., \& Vohs, K. D. (2003). Willpower, choice, and self-control. In G. Loewenstein, D. Read, \& R. Baumeister (Eds.), Time and decision: Economic and psychological perspectives on intertemporal choice (pp. 201-216). Russell Sage Foundation.

Berger, S., Wyss, A. M., \& Knoh, D. (2018). Low self-control capacity is associated with immediate responses to smartphone signals. Computers in Human Behavior, 86, 45-51. https://doi.org/10.1016/j. chb.2018.04.031

Billieux, J., Van der Linden, M., \& Rochat, L. (2008). The role of impulsivity in actual and problematic use of the mobile phone. Applied Cognitive Psychology, 22, 1195-1210. https://doi.org/10.1002/acp. 1429

Bittman, M., Brown, J. E., \& Wajcman, J. (2009). The mobile phone, perpetual contact and time. Journal Pressure Work Employment \& Society, 23(4), 1-19. https://doi.org/10.1177/0950017009344910

Boomsma, A., \& Hoogland, J. J. (2001). The robustness of LISREL modeling revisited. In R. Cudeck, S. du Toit, \& D. Sörbom (Eds.), Structural equation models: Present and future. A Festschrift in Honor of Karl Jöreskog (pp. 139-168). Lincolnwood: Scientific Software International.

Boumosleh, J. M., \& Jaalouk, D. (2017). Depression, anxiety, and smartphone addiction in university students- A cross sectional study. PLoS ONE, 12(8), e0182239. https://doi.org/10.1371/journal.pone. 0182239

Cha, S. S., \& Seo, B. K. (2018). Smartphone use and smartphone addiction in middle school students in Korea: Prevalence, social networking service, and game use. Health Psychology Open, 5(1), 1-15. https://doi.org/10.17179/excli2018-2006

Cohen, J. (1988). Statistical power analysis for the behavioral sciences. Academic Press.

Csibi, S., Griffiths, M. D., Cook, B., Demetrovics, Z., \& Szabo, A. (2018). The psychometric properties of smartphone application-based addiction scale (SABAS). International Journal of Mental Health Addiction, 16, 393-403. https://doi.org/10.1007/s11469-017-9787-2

De Pasquale, C., Sciacca, F., \& Hichy, Z. (2017). Italian validation of smartphone addiction scale short version for adolescents and young adults (SAS-SV). Psychology, 8, 1513-1518. https://doi.org/10.4236/ psych.2017.810100

de Ridder, D., Adriaanse, M., \& Fujita, K. (2017). Routledge international handbook of self control in health and well-being. Routledge Taylor and Francis. ISBN: 9781138123861.

Delvecchio, E., Mabilia, D., Lis, A., Mazzeschi, C., Nie, Y. G., \& Li, J. B. (2014). From China to Italy: Validation of the adolescent self-consciousness questionnaire. European Journal of Developmental Psychology, 11, 120-128. http://paduaresearch.cab.unipd.it/9905/1/Thesis_Jianbin_Li.pdf. Accessed 10-11-2020.

Delvecchio, E., Mabilia, D., Miconi, D., Chirico, I., \& Li, J. B. (2015). Self-consciousness in Chinese and Italian adolescents: An exploratory cross-cultural study using the Adolescent Self-Consciousness Questionnaire (ASC). Current Psychology, 34, 140-153. https://doi.org/10.1007/s12144-014-9247-0

Demirci, K., Orhan, H., Demirdas, A., Akpinar, A., \& Sert, H. (2014). Validity and reliability of the Turkish version of the smartphone addiction scale in a younger population. Klinik Psikofarmakol Bulteni, 24(3), 226-234. 
Duckworth, A. L., \& Seligman, M. E. P. (2005). Self-discipline outdoes IQ in predicting academic performance of adolescents. Psychological Science, 16(12), 939-944. https://doi.org/10.1111/j.1467-9280. 2005.01641.x

Fischer-Grote, L., Kothgassner, D. \& Felnhofer, A. (2019). Risk factors for problematic smartphone use in children and adolescents: A review of existing literature. Neuropsychiatrie, 1-12.https://doi.org/ 10.1007/s40211-019-00319-8

Flora, D. B., \& Curran, P. J. (2004). An empirical evaluation of alternative methods of estimation for confirmatory factor analysis with ordinal data. Psychological Methods, 9(4), 466-491. https://doi. org/10.1037/1082-989X.9.4.466

Gazzley, A., \& Rosen, L. D. (2016). The distracted mind: Ancient brains in a high-tech world. MIT Press.

Goodman, R. (1999). The extended version of the strengths and difficulties questionnaire as a guide to child psychiatric caseness and consequent burden. J Child Psychol Psychiatry, 40(5), 791-9.

Goodman, A., Lamping, D. L., \& Ploubidis, G. B. (2010). When to use broader internalising and externalising subscales instead of the hypothesised five subscales on the strengths and difficulties questionnaire (SDQ): Data from British parents, teachers and children. Journal of Abnormal Child Psychology, 38(8), 1179-1191. https://doi.org/10.1007/s10802-010-9434-X

Griffiths, M. D. (2005). A 'components' model of addiction within a biopsychosocial framework. Journal of Substance Use, 10(4), 191-197. https://doi.org/10.1080/14659890500114359

Hamilton, K. R., Sinha, R., \& Potenza, M. N. (2014). Self-reported impulsivity, but not behavioral approach or inhibition, mediates the relationship between stress and self-control. Journal of Addiction Behavior, 39, 1557-1564. https://doi.org/10.1016/j.addbeh.2014.01.003

Hawi, N. S., \& Samaha, M. (2016). To excel or not to excel: Strong evidence on the adverse effect of smartphone addiction on academic performance. Computers \& Education, 98, 81-89. https://doi. org/10.1016/j.compedu.2016.03.007

Hofmann, W., Luhmann, M., Fisher, R. R., Vohs, K. D., \& Baumeister, R. F. (2014). Trait self-control and well-being. Journal of Personality, 82, 265-277. https://doi.org/10.1111/jopy.12050

Kardefelt-Winther, D. (2014). A conceptual and methodological critique of internet addiction research: Towards a model of compensatory internet use. Computers in Human Behavior, 31, 351-354. https://doi.org/10.1016/j.chb.2013.10.059

Lin, Y. H., Chang, L. R., Lee, Y. H., Tseng, H. W., \& Kuo, T. B. J. (2014). Development and validation of smartphone addiction inventory (SPAI). PlosONE, 9(6), e98312. https://doi.org/10.1371/journal. pone.0098312

Marsh, H. W., \& Hocevar, D. (1988). A new, more powerful approach to multitrait-multimethod analyses: Application of second-order confirmatory factor analysis. Journal of Applied Psychology, 73, 107-111.

Mitchell, L., \& Hussain, Z. (2018). Predictors of problematic smartphone use: An examination of the integrative pathways model and the role of age, gender, impulsiveness, excessive reassurance seeking, extraversion, and depression. Behavioral Science, 8(74), 1-13. https://doi.org/10.3390/bs808 0074

Nie, Y. G., \& Ding, L. (2009). The characters of adolescent self-consciousness and its relationship with social adaptive behavior. Psychological Development and Education, 25(2), 47-54.

Nie, Y. G., Li, J. B., Dou, K., \& Situ, Q. M. (2014). The associations between self-consciousness and internalizing/externalizing problems among Chinese adolescents. Journal of Adolescence, 37, 505514. https://doi.org/10.1016/j.adolescence.2014.04.002

Nunnally, J. C. (1967). Psychometric theory. McGraw-Hill.

Pavia, L., Cavani, P., Di Blasi, M., \& Giordano, C. (2016). Smartphone addiction inventory (SPAI): Psychometric properties and confirmatory factor analysis. Computers in Human Behavior, 63, 170178. https://doi.org/10.1016/j.chb.2016.05.039

Rapporto Censis sulla situazione sociale del Paese (2018). 465-470.

Rhemtulla, M., Brosseau-Liard, P. É., \& Savalei, V. (2012). When can categorical variables be treated as continuous? A comparison of robust continuous and categorical SEM estimation methods under suboptimal conditions. Psychological Methods, 17, 354-373. https://doi.org/10.1037/a0029315

Satorra, A., \& Bentler, P. M. (1994). Corrections to test statistics and standard errors in covariance structure analysis. In A. Von Eye \& C. C. Clogg (Eds.), Latent variable analysis. Applications for developmental research (pp. 399-419). Sage.

Schermelleh-Engel, K., Moosbrugger, H., \& Muller, H. (2003). Evaluating the fit of structural equation models: Tests of significance and goodness-of-fit models. MPR-online, 8 (8): 23-74. http://www. mpr-online.de. Accessed 10-12-2020. 
Seo, D. G., Park, Y., Kim, M. K., \& Park, J. (2016). Mobile phone dependency and its impacts on adolescents' social and academic behaviors. Computers in Human Behavior, 63, 282-292. https://doi.org/10. 1016/j.chb.2016.05.026

Sinha, R. (2009). Modeling stress and drug craving in the laboratory: Implications for addictions for treatment development. Addiction Biology, 14(1), 84-98.

Simò-Sanz, C., Ballestar-Tarìn, M. L., \& Martìnez-Sabater, A. (2018). Smartphone addiction inventory (SPAI): Translation, adaptation and validation of the tool in Spanish adult population. PlosONE, 13(10), 1-12. https://doi.org/10.1371/journal.pone.0205389

Takao, M., Takahashi, S., \& Kitamura, M. (2009). Addictive personality and problematic mobile phone use. CyberPsychology \& Behavior, 12(5), 1-9. https://doi.org/10.1089/cpb.2009.0022

Tangney, J. P., Baumeister, R. F., \& Boone, A. L. (2004). High self-control predicts good adjustment, less pathology, better grades, and interpersonal success. Journal of Personality, 72, 271-324. https://doi. org/10.1111/j.0022-3506.2004.00263.x

Ten Berge, J. M. F., \& Sočan, G. (2004). The greatest lower bound to the reliability of a test and the hypothesis of unidimensionality. Psychometrika, 69, 613-625. https://doi.org/10.1007/BF02289858

Thomee, S., Hagberg, M., \& Harenstam, A. (2011). Mobile phone use and stress, sleep disturbances, and symptoms of depression among young adults-A prospective cohort study. BMC Public Health, 11, 66-76. https://doi.org/10.1186/1471-2458-11-66

Roberts, J. A., \& Pirog, S. F., III. (2012). A preliminary investigation of materialism and impulsiveness as predictors of technological addictions among young adults. Journal of Behavioral Addictions, 9, 308-314.

Rosseel, Y. (2012). lavaan: An R package for structural equation modeling. Journal of Statistical Software, 48(2), 1-36. https://doi.org/10.18637/jss.v048.i02.

van Deursen, A. J. A. M., Bolle, C. L., Hegner, S. M., \& Kommers, P. A. M. (2015). Modeling habitual and addictive smartphone behavior the role of smartphone usage types, emotional intelligence, social stress, self-regulation, age, and gender. Computers in Human Behavior, 45, 411-420. https://doi.org/ 10.1016/j.chb.2014.12.039

Wei, F. Y. F., Wang, Y. K., \& Klausner, M. (2012). Rethinking college students' self-regulation and sustained attention: Does text messaging during class influence cognitive learning? Communication Education, 61(3), 185-204. https://doi.org/10.1080/03634523.2012.672755

Widyanto, L., \& Griffiths, M. D. (2006). Internet addiction: A critical review. International Journal of Mental Health and Addiction, 4, 31-51. https://doi.org/10.1007/s11469-006-9009-9

Won, W. Y., Park, J. W., Min, J. A., Hahn, C., Gu, X., Choi, J. H., \& Kim, D. J. (2013). Development and validation of a smartphone addiction scale (SAS). PlosONE, 8, e56936. https://doi.org/10.1371/journ al.pone.0056936

World Health Organization Young people's health-a challenge for society Report of a Study Group on Young People and Health for All by the Year 2000, Technical Report Series, No 731. Geneva: World Health Organization; 1986. http://whqlibdoc.who.int/trs/WHO_TRS_731.pdf

Publisher's Note Springer Nature remains neutral with regard to jurisdictional claims in published maps and institutional affiliations. 